\title{
Comparison of mother's therapeutic touch and voice stimulus in reduce pain in premature infants undergoing invasive procedures
}

\author{
Defi Efendi, 1,2 Nining Caswini, ${ }^{3}$ Reisy Tane, ${ }^{4}$ Maria Dyah Kurniasari, ${ }^{5,6}$ Huda Mega Hasanul,5 \\ Raudha Ilmi Farid2
}

${ }^{1}$ Department of Pediatric Nursing, Faculty of Nursing, Universitas Indonesia, Depok, West Java; ${ }^{2}$ Neonatal Intensive Care Unit, Universitas Indonesia Hospital, Depok, West Java; ${ }^{3 P e d i a t r i c ~ S p e c i a l ~ C a r e ~ U n i t, ~ C i p t o ~ M a n g u n k u s u m o ~}$ Hospital, Jakarta; ${ }^{4}$ Faculty of Nursing, Health Institute Deli Husada Deli Tua, Deli Tua, North Sumatera; ${ }^{5}$ College of Nursing, Taipei Medical University, Taipei, Taiwan; ${ }^{6}$ Faculty of Medicine and Health Science, Universitas Kristen Satya Wacana, Salatiga, Central of Java, Indonesia

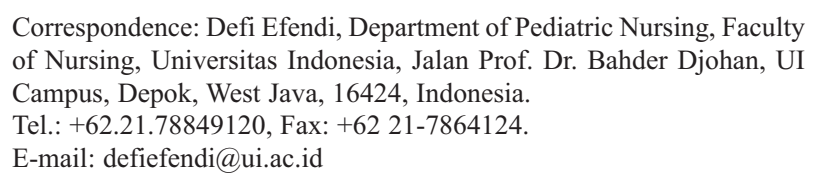

Correspondence: Defi Efendi, Department of Pediatric Nursing, Faculty of Nursing, Universitas Indonesia, Jalan Prof. Dr. Bahder Djohan, UI Campus, Depok, West Java, 16424, Indonesia.

Tel.: +62.21.78849120, Fax: +62 21-7864124.

E-mail: defiefendi@ui.ac.id

Key words: Mother touch therapy; mother voice stimulus; pain; premature infant; invasive procedures.

Acknowledgment: The author would like to thank all the nurses in Perinatology and the NICU who helped carry out this research.

Contributions: DE designed conceptualization, carried out the experiment, result interpretation, writing report, critical review of manuscript. $\mathrm{NC}$ performed experiment, collecting data, and funding acquisition. RT did data interpretation, manuscript writing. MDK and MHH conceived and designed data analysis. RIF did visualization/data presentation and edited the final report.

Conflict of interest: The authors declare no conflict of interest.

Funding: Cipto Mangunkusumo Top Referral Hospital Research Grant.

Conference presentation: This final manuscript has been presented at 7th Virtual Biennial International Nursing Conference, Faculty of Nursing, Universitas Indonesia on September 24th, October $30^{\text {th }}$, November $16^{\text {th }} 2020$.

Availability of data and materials: All data generated or analyzed during this study are included in this published article.

Ethics approval and consent to participate: The Ethics Committee of Faculty of Medicine, Universitas Indonesia approved this study (113/UN2.F1/ETIK/2016). The study is conformed with the Helsinki Declaration of 1964, as revised in 2013, concerning human and animal rights. All patients participating in this study signed a written informed consent form for participating in this study.

Consent for publication: Written informed consent was obtained from a legally authorized representative(s) for anonymized patient information to be published in this article.

Received for publication: 15 August 2020.

Accepted for publication: 9 April 2021.

This work is licensed under a Creative Commons Attribution NonCommercial 4.0 License (CC BY-NC 4.0).

CCopyright: the Author(s), 2021

Licensee PAGEPress, Italy

La Pediatria Medica e Chirurgica 2021; 43(s1):259

doi:10.4081/pmc.2021.259

\begin{abstract}
Invasive procedures commonly cause recurring pain in preterm infants. Noninvasive pain management is an essential part of nursing intervention in the Neonatal Intensive Care Unit (NICU). The study's aim is to identify the impact of touch therapy on pain in premature infants undergoing invasive treatments. The method was a quasi- experiment with 63 premature infants. The premature infants were classified into four groups: i) Mother's touch Therapy (MTT), ii) Mother's Voice Stimulus (MVS), iii) a combination of MTT and MVS, and iv) routine care. The observed infants' pain scores were determined through a multiple regression model using the Generalized Estimating Equation (GEE) method. The GEE test showed that the combination of touch and sound therapy significantly reduced pain in premature infants undergoing invasive measures $(\mathrm{p}<0.05)$. A combined application of MTT and MVS is the most effective in reducing pain scores in infants undergoing invasive procedures and thus, can used safely as part of nursing intervention in the NICU.
\end{abstract}

\section{Introduction}

Premature infants who are admitted to the Neonatal Intensive Care Unit (NICU) are exposed to various interventions and invasive procedures such as injection, which can be factors triggering neonatal pain. Research has showm that up to $70 \%$ of medical procedures performed on neonates in the NICU can cause pain. The total number of invasive procedures during the first 14 days of neonatal life has been estimated to be as high as 6832-42413, with an average of 7.5-17.3 procedures per day. ${ }^{1}$

Continous pain in neonates illness can impair brain development, decrease cognitive ability, and decrease motor skills. ${ }^{2}$ Pain has the potential to change the micro structure and function of the brain, the stress system, and stress-sensitive behavior. ${ }^{3}$ Therefore, specific measures need to be addressed in these situations.

The quality of interactions between mother and neonate in the early stage after the post-natal period can affect cognitive and emotional development in neonates. ${ }^{4}$ Physical contact between parent and premature infant in the NICU has been shown to improve the development of neurological behaviour and psychomotor development. ${ }^{5}$ Skin-to-skin contact between mother and infant increases the maturation process of the infants brain. ${ }^{6}$ 
Family centered care, which is carried out in the NICU room, has been proven to have a positive impact on infants, including stabilizing cardiorespiratory function, better sleep quality, and better pain response during treatment in the hospital. ${ }^{7}$ Involving the parent in infant care has been shown to significantly reduce the length of stay for infants in the NICU. 8

A combination of touch and holding by parents, as oppposed to other nonpharmacological therapies, such as music therapy and breastfeeding, is the most frequently introduced action to reduce pain experienced by infants in the NICU treatment room. ${ }^{9}$ Compared to oral glucose therapy, breastfeeding has high rate of pain reduction, as evidenced by behavioural responses, including decreased crying time and decreased pain scores. However, breastfeeding does not affect physical indicators, such as infant heart rate, during the NICU procedure. 10

Skin-to-skin contact therapy is an effective method for behavioral response indicators and physical responses, as evidenced by the parameters of crying time and the infants heart rate. ${ }^{2}$ The most common non-pharmacological therapy for reducing infant pain in the NICU is non-nutritive and involves -suckling, swaddling, and grasping or touching. 9 Touch stimulation can affect the infant's social, emotional, and physical well-being and has proven to reduce infants stress and pain levels while improving immune function. ${ }^{11}$ Therapeutic touch in premature infants has been shown to increase comfort through the parameters of decreased heart rate, increased oxygen saturation, increased sleep time, increased relaxation, and decreased seizure activity. ${ }^{12}$ Maternal voice is one distraction methods that should be used as a nursing intervention to reduce pain, decrease heart rate, and increase oxygen saturation in children during painful procedures in the pediatric intensive care unit. ${ }^{2}$ Auditory interventions reduce the pain and increase the comfort of premature infants. White noise is also extremely effective in preventing infants's pain. ${ }^{1}$

\section{Materials and Methods}

\section{Design}

The research method used in this study was a prospective randomized controlled trial method. Respondents were randomized into four allocated groups: i) Mother Touch Therapy (MTT), ii) Mother Voice Stimulus (MVS), iii) combined MTT + MVS, and iv) routine care. The report of this research was prepared based on Consolidated Standards of Reporting Trials (CONSORT) guidelines.

\section{Sample and Setting}

The study sample included 63 premature infants, and this number was calculated using the S-value based on Bijari et al.,13 with a value of 1.05. The inclusion criteria were defined as follows: gestational age less than 37 weeks, chronological age between 2 and 30 days, and birth weight less than 2500 grams. The exclusion criteria used in this research were as follows: i) congenital anomalies, ii) history of seizures, or iii) participation in depressant and sedative therapy. This research was conducted from March to January 2017 (Figure 1).

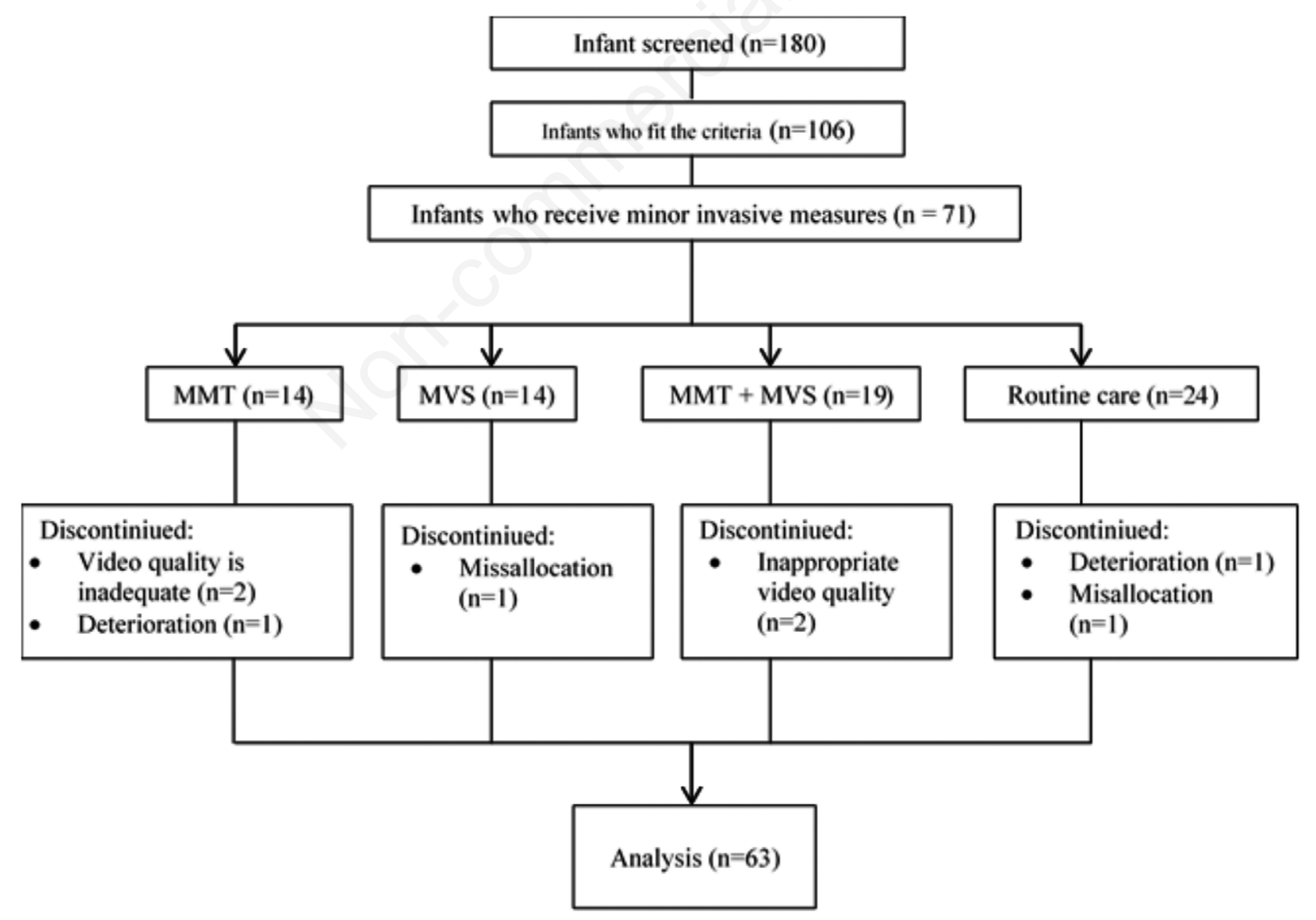

Figure 1. Flow diagram. 


\section{Data collection}

\section{Intervention}

Each premature infant who had undergone endotracheal suction, heel prick, or vein puncture was classified as having received invasive procedures. The subjects were randomly assigned to each of the following groups: i) MMT, ii) MVS, iii) MMT + MVS, and iv) routine care. Each group underwent intervention once a day for two days. The intervention was carried out in the morning or evening, with an allocated time of 15 minutes (Figure 2).

\section{Mother Therapeutic Touch (MTT)}

MTT aims to provide comfort to the infant by using the mother's hands. For our study, first, the nurse demonstrated to the mother how to wash her hands according to the World Health Organization's guidelines.

Then, the mother took the following steps: warmed her hands for 2 minutes, ${ }^{14}$ relaxed her hands and shoulders for 1 minute to focus energy on her palms, tilted the infant's position to the right or left side, bending the infants body, placing the hand near the mouth, and stretching the infant's legs closer to its stomach, and puts the palm of one hand on the infant's neck and head and rested hers other hand on the infant's lower abdomen, covering the waist and hips.

\section{Maternal Voice Stimulus (MVS)}

MVS involved the mother singing the lullaby Nina Bobo. This song was chosen because it has a constant and stable rhythm, predictable tones, and repeating lyrics. $14,15,16$ The following steps were taken: the research assistant recorded each mother's voice singing Nina Bobo 15 minutes; the volume of the voice (Krisbow KW0600291) was set to less than $65 \mathrm{~dB}$, as measured by a soundlevel meter; and a voice recording was played for 15 minutes through a speaker placed; $10-15 \mathrm{~cm}$ from the infant's head.

\section{Combination of MTT + MVS}

MTT + MVS is a combination of the MMT and MVS methods. For this study, the mother was directed by the researcher to conduct the MTT intervention, and once the mother started, the researcher played the lullaby with the volume set to less than $65 \mathrm{~dB}$ through a speaker placed $10-15 \mathrm{~cm}$ from the infant's head. The song was played turned on for 15 minutes. After 15 minutes, the procedure ended, and the mother slowly removed her hands from the infant's body.

\section{Measurement}

The researcher measured pain using the Neonatal Infants Pain Scale (NIPS). NIPS has proven to provide a valid pain scale and has excellent clinical benefits. ${ }^{17}$ The process of observing pain scores in neonates was supported by video recording the neonates from head to toe using the Sony HD-CX405 Handycam. The recording on the video was be divided into three phases: the basic phase, which took place five minutes before the intervention and was marked as 0-4 minutes (T0_T4); the therapy phase (T4-T15); and the recovery phase (T15 T29). Recording started at the fourth minutes (T4) of preparation of MTT/MVS until the end of the recovery phase (T29). Pain parameter data were gathered every two minutes consisted of NIPS parameters, including facial expression, neonatal crying, nappings pattern, limb condition (flexion or extension), and awareness (deep sleep or waking). The video footage was further reviewed by two experts, including clinical nurse specialist with at least five years working experience in the NICU. The research procedure is shown in Chart 1.

\section{Data analysis}

The homogeneity test of infant characteristic was carried out using the Levene Test for bivariate analysis. A multiple regression model was used to measure pain scores in infants using STATA for Windows and these scores were analyzed using a multiple regression model with the Generalized Estimating Equation (GEE) method.

\section{Results}

In this research, the homogeneity test was carried out using the results of statistical tests where there was no significant difference in the characteristic data between the intervention group and the control group (Table 1). Premature infants in the MTT groups showed a decrease in pain score by a factor of five. Compared to the control group, the MMT group experienced a significantly reduced in pain score one times at T15 until T19 $(p=<0.05)$ while MMT also reduced the pain score $0.91(\mathrm{p}=<0.05)$ at $\mathrm{T} 25$. We found that MMT significantly reduced pain scores 0.82 at $\mathrm{T} 27(\mathrm{p}=<0.05)$.

Group B, which underwent the MVS intervention, showed a six-times increase in pain score. Compare to the control group, the MVS group experienced a significant reduction pain score 0.82 at $\mathrm{T} 8(\mathrm{p}=<0.05)$, while MMT reduced the pain score $0.76(\mathrm{p}=<0.05)$ at $\mathrm{T} 19 ; 1.07(\mathrm{p}=<0.001)$ at $\mathrm{T} 21$; and $0.91(\mathrm{p}=<0.05)$ at T23. The results found that MMT significantly reduced the pain score 0.92 at T27 $(\mathrm{p}=<0.05)$ and 0.77 at T29 $(\mathrm{p}=<0.05)$.

The MTT + MVS intervention showed a decrease in pain score a factor of 7. Compared to the control group, MMT + MVS significantly reduced the pain score 1.49 at $\mathrm{T} 8(\mathrm{p}=<0.05) ; 1.58$ at $\mathrm{T} 10$ $(\mathrm{p}=<0.05) ; 1.45$ at $\mathrm{T} 12(\mathrm{p}=<0.05) ; 1.91$ at $\mathrm{T} 15(\mathrm{p}=<0.001) ;-1.48$ at $\mathrm{T} 17(\mathrm{p}=<0.05) ; 1.51$ at $\mathrm{T} 19(\mathrm{p}=<0.05) ; 1.52$ at $\mathrm{T} 21(\mathrm{p}=<0.05)$. Table 2 illustrates these changes.

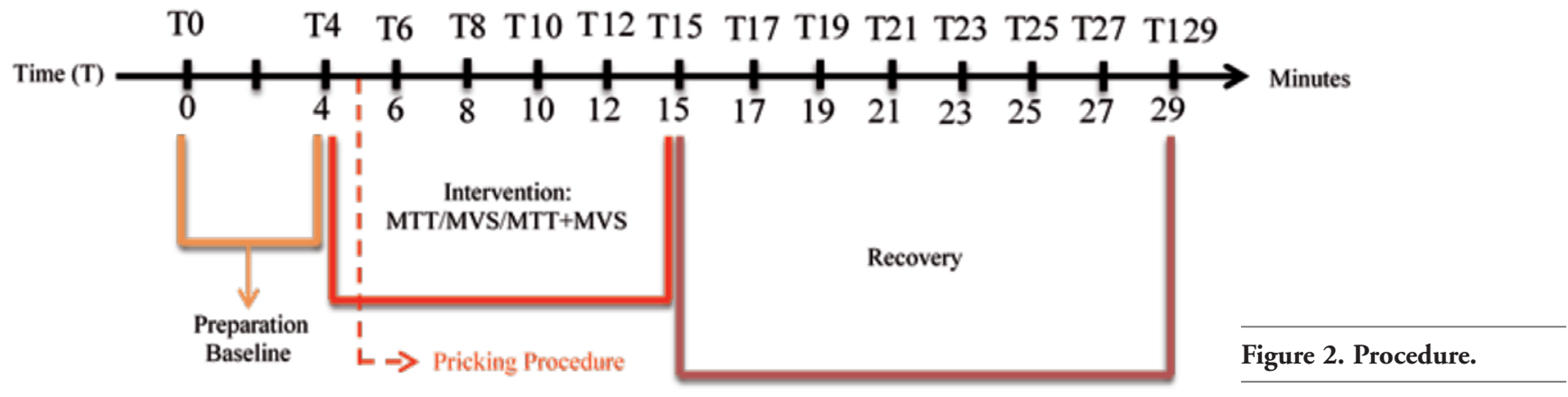




\section{Discussion}

Developmental care is needed by a premature infant to achieve optimal growth and development. One suggestion for developmental care is involving the parents in the treatment in the NICU and Special Care Nursery (SCN). According to the results of this research, MMT significantly reduced pain scores compared to the control group (p- $<0.05)$ at $15-19$ minutes. In addition, MTT also decreased pain scores at 25-27 minutes $(p<0,05)$. A reduction in pain scores was also found in infants who received significant MVS therapy at 8, 19 to 23 , and 27 minutes.

Previous research has found that giving touch intervention to premature infant undergoing suction can significantly reduce pain scores in premature infant. 18 Oktaviani et al. found that tucking or holding the hands and feet of premature infants who were stabbed during blood collection, can significantly reduce pain $(p<0.05) .{ }^{19}$ Hartley et al. also reported that tucking can reduce pain response in premature infants. ${ }^{20}$

In the current study, the mothers voice, or MVS, decreased pain during invasive actions in preterm infants at 8 minutes of the intervention $(\mathrm{T}=8)$. The mothers voice plays an important role in neurology and development in fetuses and newborns. ${ }^{15}$ Research conducted on preterm and low-birth-weight babies who listened to their mother's voice recordings found that the incidence of food intolerance was significantly less and that full feeding occurred earlier than for the control group. ${ }^{21}$

A fetus can react to sound at about 26 to 28 weeks of gestation. The fetus is able to distinguish between its mother's voice and other sounds. The mother's voice has a physiological effect on

Table 1. Infant's characteristics $(n=63)$.

\begin{tabular}{|c|c|c|c|c|c|c|c|c|c|}
\hline \multirow[t]{2}{*}{ Characteristics } & \multicolumn{2}{|c|}{ MTT (n=11) } & \multicolumn{2}{|c|}{ MVS ( $\mathrm{n}=13)$} & \multicolumn{2}{|c|}{ MIT + MVS $(n=17)$} & \multicolumn{2}{|c|}{ Routine Care ( $\mathrm{n}=22)$} & \multirow[t]{2}{*}{ p value } \\
\hline & Mean & SD & Mean & SD & Mean & SD & Mean & SD & \\
\hline \multicolumn{10}{|l|}{ Gender (n,\%) } \\
\hline Male & 11 & 50 & 10 & 48 & 10 & 48 & 14 & 70 & \multirow{2}{*}{$0.270 \mathrm{a}$} \\
\hline Female & 11 & 50 & 11 & 52 & 11 & 52 & 6 & 30 & \\
\hline Length of stay (day) & 12.80 & 8.05 & 12.20 & 7.35 & 12.50 & 7.40 & 13.20 & 7.50 & $0.977^{b}$ \\
\hline Gestational age (week) & 32.50 & 1.64 & 32.20 & 1.89 & 32.85 & 1.79 & 31.80 & 2.24 & \\
\hline Infant's age (day) & 12.30 & 7.96 & 11.65 & 7.44 & 12.05 & 7.45 & 12.70 & 7.67 & $0.507 \mathrm{~b}$ \\
\hline Infant's birth weight (gram) & 1598 & 340.67 & 1495.80 & 361.71 & 1609.75 & 254.76 & 1645.25 & 380.06 & \\
\hline Apgar score & & & & & & & & & \\
\hline At $1 \mathrm{~min}$ & 6.35 & 2.13 & 5.50 & 1.76 & 6.95 & 1.67 & 6.65 & 8.20 & $0.985^{b}$ \\
\hline At 5 min & 8.50 & 1.47 & 7.75 & 1.25 & 8.50 & 1.28 & 1.50 & 1.15 & $0.401^{b}$ \\
\hline Invasive procedure & & & & & & & & & \\
\hline ETT suctioning & 1 & 4.5 & 0 & 0 & 0 & 0 & 0 & 0 & $0.321^{\mathrm{b}}$ \\
\hline Nose and mouth suctioning & 1 & 4.5 & 3 & 14.3 & 1 & 4.8 & 1 & 5 & $0.160^{\mathrm{b}}$ \\
\hline Heel lance & 20 & 91 & 18 & 85.7 & 20 & 95.2 & 19 & 95 & $0.747 \mathrm{a}$ \\
\hline
\end{tabular}

aCochran test; bFriedman test.

Table 2. Pain score by the interventions $(n=63)$.

\begin{tabular}{|c|c|c|c|c|c|c|c|c|c|c|c|c|c|c|c|c|}
\hline & & & & & & & & & & & & & & & & \\
\hline & $\beta$ & $\begin{array}{r}\text { Routir } \\
95 \% \\
\text { Lower }\end{array}$ & $\begin{array}{l}\text { e Care } \\
\text { CI } \\
\text { Upper }\end{array}$ & $p$ & $\beta$ & $\begin{array}{r}\text { MN } \\
95 \% \\
\text { Lower }\end{array}$ & $\begin{array}{l}\text { T } \\
\text { CI } \\
\text { Upper }\end{array}$ & $p$ & $\beta$ & $\begin{array}{r}M \\
\text { Lower } \\
\end{array}$ & $\begin{array}{l}\text { S } \\
\text { CI } \\
\text { Upper }\end{array}$ & $p$ & $\beta$ & $\begin{array}{r}\text { MMT } \\
95 \% \\
\text { Lower }\end{array}$ & $\begin{array}{l}\text { MVS } \\
\text { CI } \\
\text { Upper }\end{array}$ & $p$ \\
\hline $\begin{array}{l}\text { Pain Score } \\
\text { Group*Time: }\end{array}$ & 0 & 0 & 0 & 0 & 0.05 & -0.57 & 0.66 & 0.88 & -0.23 & -0.77 & 0.31 & 0.39 & 0.13 & -0.05 & 0.72 & 0.66 \\
\hline T4 & 0 & 0 & 0 & 0 & 0 & 0 & 0 & 0 & 0 & 0 & 0 & 0 & 0 & 0 & 0 & 0 \\
\hline T6 & 0 & 0 & 0 & 0 & -0.39 & -1.14 & 0.50 & 0.45 & -0.73 & -1.51 & 0.05 & 0.07 & -0.44 & -1.16 & 0.28 & 0.23 \\
\hline T8 & 0 & 0 & 0 & 0 & -0.23 & -1.05 & 0.60 & 0.59 & -0.82 & -1.60 & -0.04 & $*<0.05$ & -0.77 & -1.49 & -0.05 & ${ }^{*}<0.05$ \\
\hline $\mathrm{T} 10$ & 0 & 0 & 0 & 0 & -0.77 & -1.60 & 0.05 & 0.07 & -0.48 & -1.26 & 0.30 & 0.23 & -0.86 & -1.58 & -0.14 & ${ }^{*}<0.05$ \\
\hline T12 & 0 & 0 & 0 & 0 & 0.14 & -.69 & 0.60 & 0.75 & -.040 & -1.17 & 0.38 & 0.32 & -0.73 & -1.45 & -0.01 & ${ }^{*}<0.05$ \\
\hline $\mathrm{T} 15$ & 0 & 0 & 0 & 0 & -1.00 & -1.82 & -0.18 & ${ }^{*}<0.05$ & -0.06 & -0.84 & 0.72 & 0.89 & -1.19 & -1.91 & -0.47 & $*<0.001$ \\
\hline T17 & 0 & 0 & 0 & 0 & -1.00 & -1.82 & -0.18 & ${ }^{*}<0.05$ & -0.36 & -1.14 & 0.42 & 0.37 & -0.76 & -1.48 & -0.04 & ${ }^{*}<0.05$ \\
\hline T19 & 0 & 0 & 0 & 0 & -1.00 & -1.82 & -0.18 & ${ }^{*}<0.05$ & -0.76 & -1.54 & 0.02 & $*<0.05$ & -0.79 & -1.51 & -0.07 & ${ }^{*}<0.05$ \\
\hline T21 & 0 & 0 & 0 & 0 & -0.68 & -1.50 & 0.14 & 0.10 & -1.07 & -1.85 & -0.29 & ${ }^{*}<0.001$ & -0.80 & -1.52 & -0.08 & ${ }^{*}<0.05$ \\
\hline T23 & 0 & 0 & 0 & 0 & -0.73 & -1.55 & 0.10 & 0.08 & -0.91 & -1.70 & -0.14 & $*<0.05$ & -0.57 & -1.29 & 0.15 & 0.12 \\
\hline T25 & 0 & 0 & 0 & 0 & -0.91 & -1.73 & -0.09 & ${ }^{*}<0.05$ & -0.61 & -1.39 & 0.17 & 0.13 & -0.57 & -1.29 & 0.15 & 0.12 \\
\hline T27 & 0 & 0 & 0 & 0 & -0.82 & -1.64 & 0.004 & $*<0.05$ & -0.92 & -1.70 & -0.14 & $*<0.05$ & -0.63 & -1.35 & 0.09 & 0.09 \\
\hline Т29 & 0 & 0 & 0 & 0 & -0.5 & -1.32 & 0.32 & 0.23 & -0.77 & -1.55 & 0.01 & ${ }^{*}<0.05$ & -0.40 & -1.12 & 0.31 & 0.27 \\
\hline
\end{tabular}


behavior and emotion in premature babies. A systematic review conducted by Williamson and McGrath found that several studies have explained that the mother's voice increases the stability of the autonomic nerves, especially heart rate and respiration, and can increase the weight of premature babies. ${ }^{22}$

The current research found that the combination of MMT and MVS significantly reduced pain scores at 8-21 minutes, as compared to the control group. This is in line with previous research by Qiu et al. who conducted a study on 62 premature infants who received 3707 invasive treatments while in the hospital, and found that those who received a combination of music and touch therapy experienced a significant reduction in pain scores, as compared to the control group. The combination of music and touch therapy decreased the pain response in premature infants by significantly increasing the beta endorphin concentration. ${ }^{3}$

Therapeutic touch in preterm infants with a correction age of 34-40 weeks can significantly increase the concentration of oxygen hemoglobin but does not affect the baby's heart rate, oxygen saturation, or body movements. ${ }^{23}$ The results of this study are not in line with research conducted by Jhonston et al. who found that therapeutic touch given to infants who received invasive measures did not affect the pain response in infants. This difference may be due to the different interventions given to premature babies. ${ }^{2}$

The combination of gentle human touch and the mother's voice can affect the behavior of premature babies. Gentle touch can have a calming effect on babies. Soft touch can improve the baby's sleep so that it can reduce energy use and dependence on $\mathrm{O}_{2}$ therapy in the first week of hospitalization in the NICU room. ${ }^{13}$ The mother's voice can provide sensory stimulation to the fetus to provide elicit a psychological response for fetal development. Exposure to the mother's voice provides a safe and comfortable environment for premature babies. Early exposure to the mother's voice has a beneficial effect on the development of autonomic and neurobehavioral nerves in preterm infants. ${ }^{24}$

\section{Conclusions}

Implementation of MTT + MVS significantly reduced the pain score according to NIPS. Lower pain levels in infants can increase optimal care in the NICU. MTT + MVS therapy can also improve mother-infant bonding, especially when the infant is undergoing treatment in the NICU for during the first 24 hours of life. Implementation of this therapy by nurses; can effectively place focus on family-centered care in the NICU.

\section{References}

1. Cruz MD, Fernandes AM, Oliveira CR. Epidemiology of painful procedures performed in neonates: a systematic review of observational studies. Eur J Pain 2016;20:489-98.

2. Johnston C, Campbell-Yeo M, Disher T, et al. Skin-to-skin care for procedural pain in neonates. Cochrane Database Syst Rev 2017;2:CD008435.

3. Qiu J, Jiang YF, Li F, et al. Effect of combined music and touch intervention on pain response and $\beta$-endorphin and cortisol concentrations in late preterm infants. BMC Pediatr 2017;17:38.

4. Korja R, Latva R, Lehtonen L. The effects of preterm birth on mother-infant interaction and attachment during the infant's first two years. Acta Obstet Gynecol Scand 2012;91:164-73.

5. Montirosso R, Provenzi L, Calciolari G, et al. Measuring mater- nal stress and perceived support in 25 Italian NICUs. Acta Paediatr 2012;101:136-42.

6. Kaffashi F, Scher MS, Ludington-Hoe SM, Loparo KA. An analysis of the kangaroo care intervention using neonatal EEG complexity: a preliminary study. Clin Neurophysiol 2013;124:238-46.

7. Jefferies AL, Canadian Paediatric Society, Fetus and Newborn Committee. Kangaroo care for the preterm infant and family. Paediatr Child Health 2012;17:141-6.

8. Segers E, Ockhuijsen H, Baarendse P, et al. The impact of family centred care interventions in a neonatal or paediatric intensive care unit on parents' satisfaction and length of stay: a systematic review. Intensive Crit Care Nurs 2019;50:63-70.

9. Pillai Riddell RR, Racine NM, Gennis HG, et al. Non-pharmacological management of infant and young child procedural pain. Cochrane Database Syst Rev 2015;2015:CD006275.

10. Paixão MJG. Breastfeeding for procedural pain in infants beyond the neonatal period. Clin Nurse Spec 2018;32:116-7.

11. Field T. Touch for socioemotional and physical well-being: a review. Dev Rev 2010;30:367-83.

12. Hanley MA, Coppa D, Shields D. A practice-based theory of healing through therapeutic touch: advancing holistic nursing practice. J Holist Nurs 2017;35:369-81.

13. Bijari BB, Iranmanesh S, Eshghi F, Baneshi MR. Gentle human touch and yakson: the effect on preterm' s behavioral reactions. ISRN Nurs 2012;2012:750363.

14. Alipour Z, Eskandari N, Ahmari Tehran H, et al. Effects of music on physiological and behavioral responses of premature infants: a randomized controlled trial. Complement Ther Clin Pract 2013;19:128-32.

15. Gargano G, Nuccini F. Maternal voice and preterm infants development. Ital J Pediatr 2015;41:A14.

16. Neal DO, Lindeke LL. Music as a nursing intervention for preterm infants in the NICU. Neonatal Netw 2008;27:319-27.

17. Malarvizhi G, Vatsa M, Roseline M, et al. Inter-rater reliabilty of neonatal infant pain scale (NIPS) as a multidimensional behavioral pain tool. Journal of Health and Allied Sciences NU 2012;02:26-30.

18. Cignacco E, Hamers JP, van Lingen RA, et al. Pain relief in ventilated preterms during endotracheal suctioning: a randomized controlled trial. Swiss Med Wkly 2008;138:635-45.

19. Oktaviani E, Rustina Y, Efendi D. Facilitated tucking effective to pain relief on the preterm infants in perinatal unit in Jakarta. Jurnal Keperawatan Indonesia 2018;21:9-16.

20. Hartley KA, Miller CS, Gephart SM. Facilitated tucking to reduce pain in neonates: evidence for best practice. Adv Neonatal Care 2015;15:201-8.

21. Krueger C. Exposure to maternal voice in preterm infants: a review. Adv Neonatal Care 2010;10:13-8.

22. Williamson S, McGrath JM. What are the effects of the maternal voice on preterm infants in the NICU? Adv Neonatal Care 2019;19:294-310.

23. Honda N, Ohgi S, Wada N, et al. Effect of therapeutic touch on brain activation of preterm infants in response to sensory punctate stimulus: a near-infrared spectroscopy-based study. Arch Dis Child Fetal Neonatal Ed 2013;98:F244-8.

24. Picciolini O, Porro M, Meazza A, et al. Early exposure to maternal voice: effects on preterm infants development. Early Hum Dev 2014;90:287-92. 